\title{
ADJUSTMENT OF REACTOR MODEL IN ORGANIC MATTER REMOVAL FROM WASTEWATER APPLYING NUMERICAL RESIDENCE TIME DISTRIBUTION ANALYSIS
}

\author{
TAMAS KARCHES \\ Institute of Water Supply and Environmental Engineering, National University of Public Service, Hungary.
}

\begin{abstract}
Mass balance models in wastewater treatment may overpredict the organic matter degradation in aerated basins, because the simulation tools apply simplified reactor models, which could not represent the actual hydrodynamic and mixing conditions in the reactors. Ineffective reactor zones, short hydraulic circuits could have an effect on the actual performance of treatment process. In this paper, a wastewater treatment plant with a capacity of 10 MLD was investigated, where residence time distribution (RTD) analysis performed with computational fluid dynamics tools determined the actual time for biodegradation, and the biokinetic model could be updated. For the numerical RTD analysis 3D transient multiphase flow with turbulence closure was applied, whereas mass balance modelling used GPS-X simulation tool calibrated by field data. The model results were in good agreement with the measured chemical oxygen demand, total suspended solid values in treated effluent, and this method highlighted the importance of extension of mass balance modelling with hydrodynamic calculations. Keywords: mass balance modelling, organic matter, reactor models, wastewater treatment.
\end{abstract}

\section{INTRODUCTION}

The majority (90\%) of water supply in Hungary is based on subsurface water sources. In order to protect these resources, used water shall undergo a treatment process before releasing it to receiving water bodies. Medium or large size municipalities apply centralized solution with large channel systems, which collect and transport the wastewater to treatment plants, where biodegradation processes reduce the organic matter and nutrient content of wastewater. Nowadays decentralized solutions are again in focus in Hungary aiming to treat the wastewater locally [1], where it is produced by applying the same biochemical processes as in large scale plants.

Wastewater treatment is a combination of various processes which could be separated into mechanical, biological, chemical and post-treatment stages. The mechanical stage applies screens, grit chamber, in some cases primary sedimentation tanks, the biological stage equips various environments (e.g. anoxic, aerobic, etc.) for microorganisms each responsible for different processes (e.g. nitrification, denitrification, enhanced biological removal, etc). Chemical treatment is basically responsible for phosphorous removal and enhance the phase separation [2]. The 4th stage of wastewater treatment is applied for removal of micro pollutants or polishing the effluent in order to close the urban water cycle.

Wastewater treatment modelling is a complex system with numerous sub-models which are interconnected. Each element has its own significance and purpose. The International Water Association Good Modelling Practice Task Group developed a model structure, its key parts were the mass balance, hydrodynamic, aeration and clarifier models, the submodels were the controller, sensor and influent/effluent models. Mass balance modelling takes into account the wastewater constituents as scalars and transport equations describe bio-chemical processes. Activated sludge modelling family (ASM1, ASM2d and ASM3) 
describes the suspended growth and decay of biomass, oxygen consumption, organic matter and nutrient degradation [3]. In these models, the hydraulic conditions are simplified, and reactor models are built using the simulation tools to determine the mixing conditions (completely stirred tank reactor, plug flow reactor or any combination of the two idealized reactor model). Calibration of the mass balance model is based on direct measurement of kinetic parameters or following reversed engineering by the knowledge of the actual plant effluent data.

Efficiency of wastewater treatment processes is highly dependent on the flow behaviour and mixing regimes. Wastewater treatment requires oxygenation, which is generally supplied by a diffuser network that provides the required oxygen in aerobic tanks. The aim of aeration is twofold: it provides the necessary oxygen for the biomass and gives movement to the water phase, and it creates appropriate mixing conditions. Mixing is sufficient only if the substrate could be transported to the biomass and side products from the biological activity can be transported out of the system. For understanding these complex features of fluid flow, numerical analysis of fluid flow is required with which the turbulent velocity field can be fully resolved over the simulation domain.

Computational fluid dynamics (CFD) simulation tools are popular in wastewater treatment, numerous research have been done regarding hydraulic aspects of treatment process units, but many processes are not addressed to date [4]. CFD models have primarily been used for design analysis and troubleshooting, but they can be coupled with mass balance (biokinetic) models in which the tank-in-series (TIS) approach is applied widely [5]. It has also been reported that biokinetic models are calibrated by forcing a TIS model to match available data to model parameters, in spite of the fact that TIS neglects the hydrodynamic details of the system [6], especially the small-scale phenomena such as short circuiting and possible dead-zone formation. Applying compartmental models based on CFD calculations [7], the mixing is more detailed compared to TIS, but constructing each compartment zone and connectivity is case-specific.

Biokinetic calculations can theoretically be performed by the extension of the governing equations of fluid flow with scalar equations for biomass, substrate and dissolved oxygen [8], but the processes taken into account are limited. Meister and Rauch [9] were able to couple smoothed particle hydrodynamic approach to ASM1 model, but Reynolds Averaged Navier Stokes (RANS) based models are also proved to be efficient to model an oxidation ditch [10], however more detailed biochemical processes like nitrification/denitrification in ASM2D or Anammox in Mantis model [11] are not effectively coupled with CFD to date.

Based on the literature review, it can be stated that there should be an agreement between the resolution of flow field and the number of biokinetic parameters. Even in simple geometries, transient turbulent multiphase 3D flows have increased the computational capacity need. The aim of this research is to demonstrate the applicability of residence time distribution (RTD) analysis in mass balance modelling.

\section{MATERIAL AND METHODS}

An aerated basin designed for $10,000 \mathrm{~m}^{3} / \mathrm{d}$ treatment capacity was investigated. The basin geometry is rectangular, and it has a length of $25 \mathrm{~m}$, width of $7.7 \mathrm{~m}$ and a depth of $5 \mathrm{~m}$. Disc diffusers with 9" diameter were installed $20 \mathrm{~cm}$ from the bottom to prevent fouling from undesired particle settling. Primary-treated wastewater enters the basin $1.5 \mathrm{~m}$ above the bottom in a submerged pipe with a diameter of $30 \mathrm{~cm}$, and the effluent leaves the system on the right-hand side as shown in Fig. 1. 


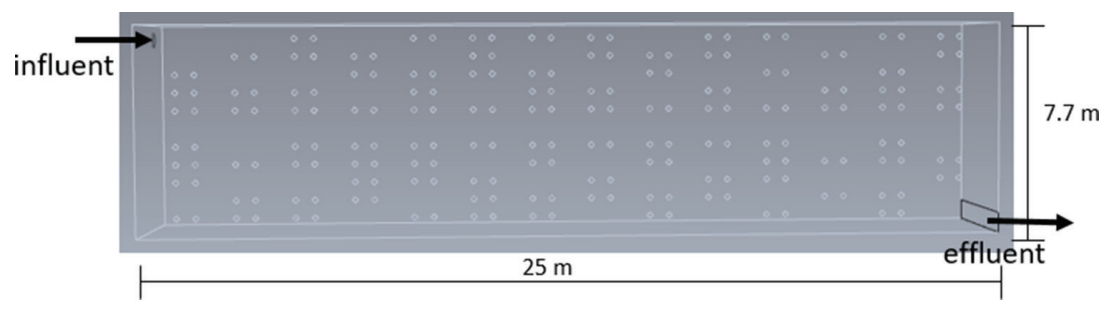

Figure 1: Aerated basin geometry (top view).

The analysis could be divided into the following steps:

- determination of the flow field in aerated basin applying CFD simulation,

- RTD analysis by Lagrangian particle tracking,

- adjustment of TIS model and

- performing mass balance simulations.

\subsection{Determination of flow field}

Flow field simulation procedure includes the following: drawing the geometry, mesh generation (spatial discretization), boundary and initial condition setup, numerical solver selection, iteration and convergence criteria and evaluation of the flow field.

The discretized domain consisted of 383780 tetrahedral sub-volumes and 779495 nodes, applying size function at the inlet, outlet section and around the diffusers. Inlet boundary was a constant mass flow neglecting the effect of diurnal pattern of wastewater loading. From the diffuser surface $2 \mathrm{~m}^{3} / \mathrm{h}$ air is introduced to the system. The surface of the basin lets the gas out from the system (degassing) and the outflow zone was pressure outlet. Steady-state RANS model with $k-\varepsilon$ turbulence closure was applied. Despite the fact that this approach assumes isotrophic turbulence [12], it is well tested and widely accepted in wastewater applications [4]. SIMPLE (Semi-Implicit Method for Pressure Linked Equations) scheme was applied for velocity-pressure coupling and second-order upwind techniques was applied for spatial discretization [13]. Convergence criteria were the stability of iteration residuals and the quasipermanent flow field.

Simulation of air-induced flow and the moment of exchange between the gas-liquid phase were modelled by Eulerian-Eulerian approach [14]. Volume fraction of air as a scalar was additionally solved during the entire calculation process.

\subsection{RTD analysis and TIS model}

The objective of introducing a tracer to the system is to gain information of the fluid path lines and the time required to go through the basin. In field experiments the tracer is mainly a conservative material which is not present in the background flow, has no intention for decay or react and relatively easy to detect. In a numerical model, the tracer can have the same properties as the primary fluid. Injecting the tracer to the pre-calculated steady-state flow field could reveal the difference in travel times of the various particles. $E(t)$ is the distribution function of the normalized tracer concentration calculated by the ratio of the exiting 


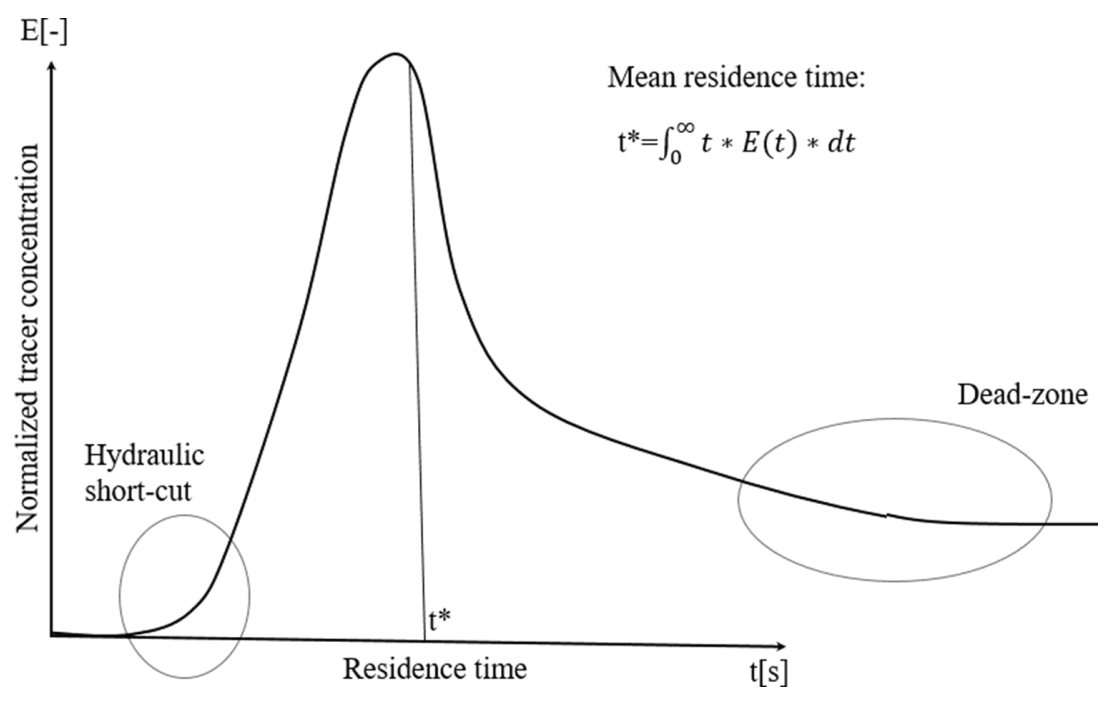

Figure 2: RTD curve.

particles at a given time and the total particles. If some tracer particles are present at the effluent shortly after the injection, it indicates the hydraulic shortcuts in the basin, whereas long travel time means that some particles are trapped in a stagnant zone (see Fig. 2).

The first-order moment of $E(t)$ is the average residence time, and the second-order moment is the standard deviation [15]. From these two variables the Peclet (Pe) number can be calculated that indicates a convective transport rate to diffusion rate. High Pe number means plug flow mixing behaviour without axial dispersion, whereas low Pe indicates completely mixed conditions. In wastewater treatment reactors or basins Pe is normally between 1 and 50 [16], meaning that the actual mixing condition is somewhere between the two idealized approaches. By applying Pe number, the cascading of the completely stirred tank reactors can be determined and then used in mass balance modelling.

\subsection{Mass balance model}

Mathematical formulation of the main scalar variables based on the transport equation, where the kinetic term can be decomposed to process rates and stoichiometric constants. The growth of the heterotrophic biomass can be described as follows:

$$
\frac{d X_{H}}{d t}=(+1) \cdot \mu_{H} \cdot \frac{D O}{K_{H, O_{2}}+D O} \cdot \frac{S S}{K_{H, S S}} \cdot X_{H},
$$

where $\mu_{H}$ is the maximum specific growth rate (1/d), DO the dissolved oxygen concentration $(\mathrm{g} / \mathrm{L}), K_{\mathrm{H}_{3} \mathrm{O}_{2}}$ the half-saturation coefficient of oxygen $(\mathrm{g} / \mathrm{L}), S S$ the soluble substrate concentration $(\mathrm{g} / \mathrm{L}), K_{H, S S}$ the half-saturation coefficient of soluble substrate $(\mathrm{g} / \mathrm{L})$ and $X_{H}$ the heterotrophic biomass concentration $(\mathrm{g} / \mathrm{L})$.

Calibration of the biokinetic model can be a step-wise procedure by changing the lowest number of parameters. Steady-state calibration follows the logic of adjusting the selected parameters in order to match the effluent composite or state variables describing the organic content: total suspended solid (TSS) and chemical oxygen demand (COD) and COD fractions. 


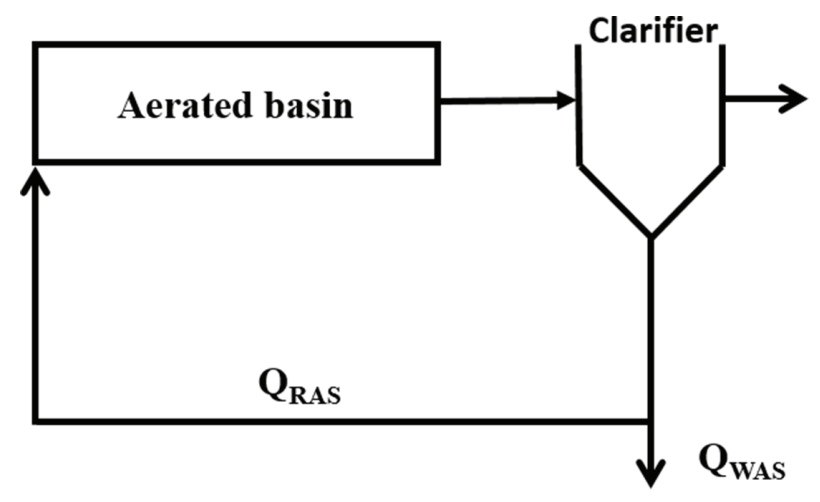

Figure 3: Simplified process scheme of the activated sludge treatment.

Data for calibration was taken from a system, where the biomass amount was stable over time. 24-h composite COD and TSS measurements were performed for a week. Samples were taken from the influent and effluent. After the sampling and laboratory measurements, plausibility check and reconciliation were performed. Dissolved oxygen concentration was $2.5 \mathrm{mg} / \mathrm{L}$, and thus oxygenation is not a limiting factor in organic matter degradation, therefore it is enough to adjust the heterotrophic biomass yield and decay rate in the calibration process.

Only organic matter degradation was aimed in this system, therefore the process scheme could have been simplified (Fig. 3). In order to increase the solid retention in aerated basin, part of the recirculated sludge (RAS: recirculated activated sludge) is reverted to the aeration basin. Wasted activated sludge (WAS) is a portion of sludge sent to the sludge line for stabilization and dewatering. Basically RAS is responsible for maintaining the elevated activated sludge concentration (in other words: mixed liquor concentration, MLSS) in the aerated basin, and WAS controls the solid retention time.

\section{RESULTS AND DISCUSSION}

Steady-state CFD simulations were performed in order to determine the flow field. Average dry weather flow of $Q=10$ MLD plus RAS flow of $0.8 \mathrm{Q}$ was set at the inlet boundary, resulting in a relatively high inlet velocity of $2.1 \mathrm{~m} / \mathrm{s}$. The integral averaged velocity in the entire basin was $0.11 \mathrm{~m} / \mathrm{s}$, from which the vertical component was only $0.7 \mathrm{~cm} / \mathrm{s}$ primarily causing the aeration. Horizontal velocity was more than one order of magnitude higher compared to vertical velocity. Figure 4 shows that the influent flow momentum governs the entire flow field, which may cause short circuiting. It will be advisable to apply distributed inlet instead of a point-like influent source.

RTD analysis was performed by releasing 1000 particles through the inlet section at various integration step and time, and in each case the incomplete and existing particles were calculated. The theoretical residence time calculated by the ratio of the basin volume of the incoming flow was $1.28 \mathrm{~h}$. In a tracer study, the first particle appeared at the effluent section only spent $950 \mathrm{~s}$ in the reactor, whereas little more than $10 \%$ of the particles remained in the system for more than $2 \mathrm{~h}$. The cumulative function of the numerical RTD can be seen in Fig. 5. The average residence time from the curve is $0.83 \mathrm{~h}$, which is lower than the theoretical value. The cause of the difference is in the non-ideal flow field, the presence of turbulent jet caused by the inlet geometry. This result leads to the hypothesis that the mass balance model, which assumes the higher residence time, overpredicts the biodegradation performance of this system. 


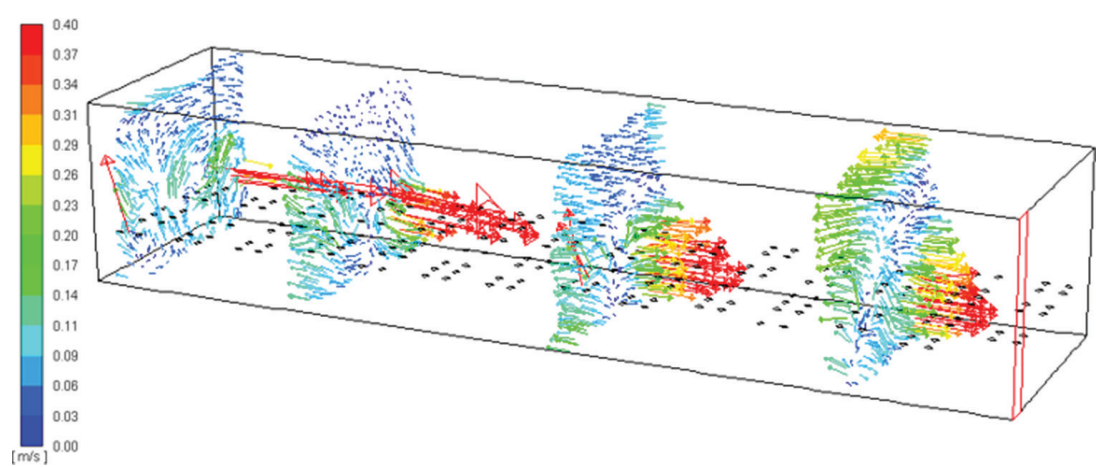

Figure 4: Velocity vectors at sections $(\mathrm{m} / \mathrm{s})$.

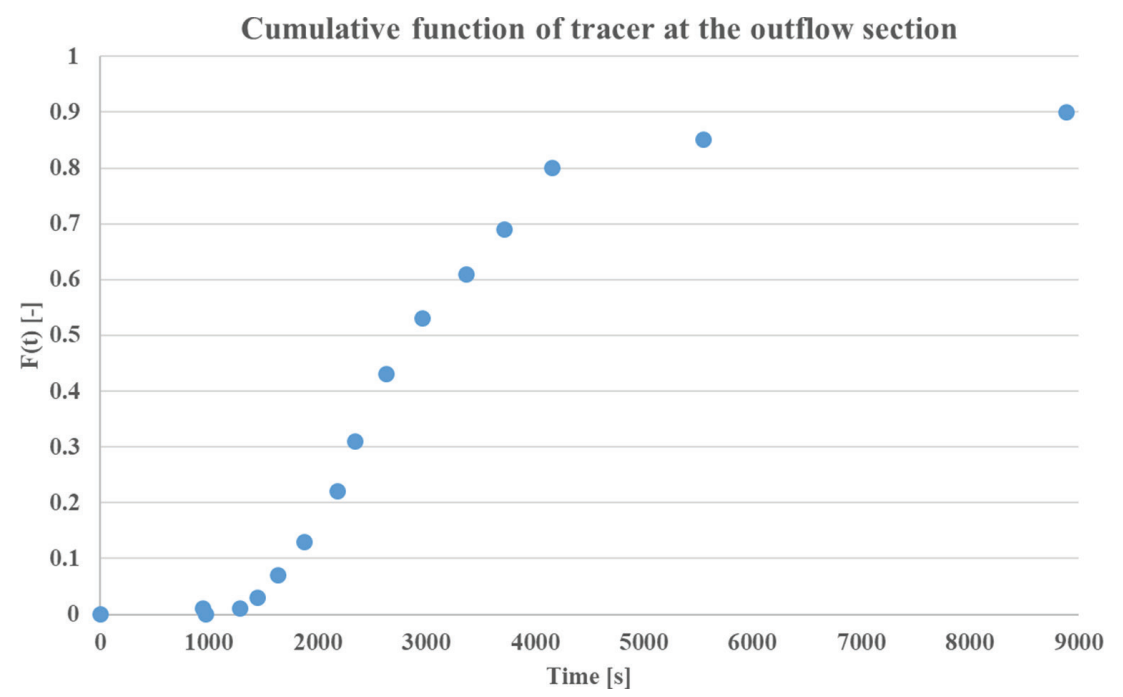

Figure 5: Cumulative function of tracer at the outflow section.

Standard deviation of the residence time is $915 \mathrm{~s}$. The Peclet number is 21.15 , the number of cascaded reactors is approximately 11 . The diffusivity is 0.047 ; a value close to the plug flow reactor's mixing condition [17].

In the following mass balance model was developed as described in Section 2. Firstly, influent characterization was done, various COD fractions were calculated. The incoming $820 \mathrm{mg} / \mathrm{L}$ total COD can be fractionated as follows: slowly biodegradable particulate: $425 \mathrm{mg} / \mathrm{L}$, non-biodegradable particulate $102 \mathrm{mg} / \mathrm{L}$, soluble biodegradable $249 \mathrm{mg} / \mathrm{L}$, inert soluble $44 \mathrm{mg} / \mathrm{L}$, reflecting a typical raw communal wastewater quality. The soluble biodegradable fraction is ready for the instant use of heterotrophic microorganisms, thus it projects an effective denitrification process. TSS in the raw influent was $432 \mathrm{mg} / \mathrm{L}$, from which $80 \%$ was the organic content. Table 1 shows the detailed influent variables as well as the effluent data. Plant effluent is the measured average treated water quality comes from laboratory measurements.

ASM2d model was applied in GPS-X 6.5 simulation environment, the plant layout was constructed and fed with dimensional and operational data. MLSS concentration in the 
Table 1: Wastewater quality in influent and treated effluent.

\begin{tabular}{ccccc}
\hline & Raw influent & Plant effluent & $\begin{array}{c}\text { Model effluent } \\
\text { (1 basin) }\end{array}$ & $\begin{array}{c}\text { Model effluent } \\
\text { (adjusted model) }\end{array}$ \\
\hline COD & 820 & 102 & 75 & 86 \\
$\mathrm{BOD}_{5}$ & 320 & 20 & 14 & 17 \\
$\mathrm{TSS}$ & 432 & 23 & 16 & 22 \\
$\mathrm{TN}$ & 85 & 22 & 20 & 25 \\
$\mathrm{NH}_{4}-\mathrm{N}$ & 59 & 2.3 & 1.0 & 1.2 \\
\hline
\end{tabular}

aerated basin was $3.5 \mathrm{~g} / \mathrm{L}$, the aerobic sludge retention time was $2.4 \mathrm{~d}$ which is sufficient for organic removal at temperature of $20^{\circ} \mathrm{C}$. Wasted sludge flow was $200 \mathrm{~m}^{3} / \mathrm{d}$ at dry solid concentration of $7 \mathrm{~g} / \mathrm{L}$. The dissolved oxygen concentration was $2.5 \mathrm{mg} / \mathrm{L}$.

Applying calibration process described in Section 2, the aerobic heterotrophic yield and aerobic heterotrophic decay rate was adjusted. The previous one had a value of $0.75 \mathrm{gCOD} / \mathrm{gCOD}$, the latter one was $0.61 / \mathrm{d}$.

Two modelling scenarios were calculated. One with a compartment reactor, which is completely mixed, and the other one is a cascaded reactor system, in which the cascade element number came from CFD simulation-adjusted model, assuming 11 reactors in cascade. Table 1 contains the model effluent data showing that one element cascade overpredicted the performance of organic matter degradation. However, there is a discrepancy between the adjusted model and plant effluent COD data. The reasons could be the lack of data on the model variables (fractions). Besides this fact, the clarifier model might have overpredicted thickening, resulting lower TSS value modelled compared to experimental result.

Neglecting these effects a simple sensitivity analysis revealed that if the cascade element number is increased or decreased by 1,2 or 3 elements, the modelled effluent COD concentrations differed only $2 \%, 3.5 \%$ and $6 \%$, respectively. It should be noted that although there is no significant effect of compartment number at these relatively high reactor numbers, but if one or two reactor number is changed to three or four, the impact would be higher. Other aspect of cascading reactors is the sludge production, which can be reduced in case of plug flow; different substrate concentrations are favoured by the microorganisms, and a so-called food chain could be presented if there is no high axial dispersion. In food chain reactors higher order microorganisms consume the protozoa or simple organisms reduce the TSS.

\section{CONCLUSIONS}

The efficiency of wastewater treatment processes is determined by biological as well as hydrodynamic conditions. Mass balance (biokinetic) modelling often simplifies the mixing conditions in reactors and may cause discrepancies in the estimation of treated effluent wastewater quality. The capacity of wastewater treatment plants can be overestimated that may lead to violation of effluent quality requirement. CFD simulations could reveal the actual mixing conditions within the aeration basin. Multiphase modelling was performed in a biological reactor, in which aeration induced flow creates a vertical flow, the influent discharge is responsible for horizontal movement of the substrate and biomass. Mixing zones were separated and cascade element number was determined by numerical RTD analysis. Reactor compartment number was adjusted in mass balance modelling, the environment and organic 
removal was investigated and compared with field data. It could be stated that applying adjusted model is in close agreement with field data, but there are still discrepancies. Furthermore, it can be added that assuming idealized reactor models it may overpredict process performances, therefore the real flow and mixing conditions shall be explored prior mass balance modelling. In the future, process parameters shall also be calibrated against actual flow conditions.

\section{ACKNOWLEDGEMENTS}

This work has been undertaken as a part of a project founded by the EFOP-3.6.1-16-201600025 aiming for the development of water management in Higher Education in the frame of intelligent specialization.

\section{REFERENCES}

[1] Somogyi, V., Pitas, V., Domokos, E. \& Fazekas, B., On-site wastewater treatment systems and legal regulations in the European Union and Hungary. Agriculture and Environment, 1, pp. 57-64, 2009.

[2] Tchobanoglus, G., Burton, F. \& Stensel, H.D., Wastewater engineering: treatment and reuse. American Water Works Association Journal, 95(5), p. 201, 2003.

[3] Henze, M., Gujer, W., Mino, T. \& van Loosdrecht, M.C., Activated Sludge Models ASM1, ASM2, ASM2d and ASM3, IWA Publishing, 2000.

[4] Samstag, R.W., Ducoste, J.J., Griborio, A., Nopens, I., Batstone, D.J., Wicks, J.D. \& Laurent, J., CFD for wastewater treatment: an overview. Water Science and Technology, 74(3), pp. 549-563, 2016. https://doi.org/10.2166/wst.2016.249

[5] Wicklein, E., Batstone, D.J., Ducoste, J., Laurent, J., Griborio, A., Wicks, J.... \& Nopens, I., Good modelling practice in applying computational fluid dynamics for WWTP modelling. Water Science and Technology, 73(5), pp. 969-982, 2016. https:// doi.org/10.2166/wst.2015.565

[6] Alvarado, A., Vedantam, S., Goethals, P. \& Nopens, I., Compartmental models to describe hydraulics in full-scale waste stabilization ponds. Water Research, 46(2), pp. 521-530, 2012. https://doi.org/10.1016/j.watres.2011.11.038

[7] Le Moullec, Y., Gentric, C., Potier, O. \& Leclerc, J.P., Comparison of systemic, compartmental and CFD modelling approaches: application to the simulation of a biological reactor of wastewater treatment. Chemical Engineering Science, 65(1), pp. 343-350, 2010. https://doi.org/10.1016/j.ces.2009.06.035

[8] Rehman, U., Maere, T., Vesvikar, M., Amerlinck, Y. \& Nopens, I., Hydrodynamicbiokinetic model integration applied to a full-scale WWTP. In 9th IWA World Water Congress and Exhibition, 2014.

[9] Meister, M. \& Rauch, W., Wastewater treatment modelling with smoothed particle hydrodynamics. Environmental Modelling \& Software, 75, pp. 206-211, 2016. https:// doi.org/10.1016/j.envsoft.2015.10.010

[10] Karpinska, A.M. \& Bridgeman, J., CFD-aided modelling of activated sludge systems-a critical review. Water Research, 88, pp. 861-879, 2016. https://doi.org/10.1016/j.watres.2015.11.008

[11] Bencsik, D. \& Karches, T., Modelling greenhouse gas emissions of a hybrid fixedfilm anammox process treating sludge dewatering centrate in wastewater treatment. British Journal of Environment and Climate Change, 6(4), pp. 250-258, 2016. https:// doi.org/10.9734/bjecc/2016/26725 
[12] Launder, B.E. \& Spalding, D.B., The numerical computation of turbulent flows. Numerical Prediction of Flow, Heat Transfer, Turbulence and Combustion, Pergamon, pp. 96-116, 1983. https://doi.org/10.1016/b978-0-08-030937-8.50016-7

[13] Ferziger, J.H. \& Peric, M., Computational methods for fluid dynamics. Springer Science \& Business Media, 2012.

[14] Pfleger, D., Gomes, S., Gilbert, N. \& Wagner, H.G., Hydrodynamic simulations of laboratory scale bubble columns fundamental studies of the Eulerian-Eulerian modelling approach. Chemical Engineering Science, 54(21), pp. 5091-5099, 1999. https:// doi.org/10.1016/s0009-2509(99)00261-4

[15] Fogler, H.S., Essentials of Chemical Reaction Engineering: Essential Chemical Reaction Engineering, Pearson Education, 2010.

[16] Ke, T., Tao, T.W.Z.Y.J. \& Tian, L.X.L., Impact of Peclet number on heat transfer of oscillatory flow in circular channel. Cryogenics, 3, p. 2, 2011.

[17] Khudenko, B.M. \& Shpirt, E., Hydrodynamic parameters of diffused air systems. Water Research, 20(7), pp. 905-915, 1986. https://doi.org/10.1016/0043-1354(86)90180-6 